\title{
Ethical Issues in Treating Self and Family Members
}

\author{
E. B. Anyanwu ${ }^{1, *}$, Harrison O. Abedi ${ }^{2}$, Efe A. Onohwakpor ${ }^{2}$ \\ ${ }^{1}$ Department of Family Medicine, Delta State University Teaching Hospital, Oghara, P.M.B. 07, Oghara, Nigeria \\ ${ }^{2}$ Department of Obstetrics and Gynaecology, Delta State University Teaching Hospital, Oghara, P.M.B. 07, Oghara, Nigeria \\ *Corresponding author: ebirian@yahoo.com
}

Received March 28, 2014; Revised May 07, 2014; Accepted May 07, 2014

\begin{abstract}
A trained health care provider principally offers care to ill-patients, offers advocacy to groups of persons, could be a passionate counsellor when needed, and may offer preventive services to individuals and communities at large. He is trained to alleviate the problem of sickness from patients. Therefore, a patient may just as well be the physician himself or may be his immediate family members who can fall ill and so needs the expertise of a doctor. The patient maybe a colleague, friend or employee who all maybe intimate with the physician but may need his services when they are ill. The challenge therefore, is when does the doctor stop doctoring a patient and transfer care to another doctor. What risks may show up if a doctor treats himself and close family members? Is it ethical for a doctor not to offer treatment solely on the ground that the patient is a close relation?
\end{abstract}

Keywords: patient, physician, treatment, family, doctor, ethics

Cite This Article: E. B. Anyanwu, Harrison O. Abedi, and Efe A. Onohwakpor, "Ethical Issues in Treating Self and Family Members.” American Journal of Public Health Research, vol. 2, no. 3 (2014): 99-102. doi: 10.12691/ajphr-2-3-6.

\section{Case Observation}

A case was unofficially mentioned among colleagues of a doctor who performed an appendectomy operation on his own sister who apparently developed an acute appendicitis and needed surgery to be done. Apparently, the doctor had the appropriate skills to perform the surgery, but there were other equally skilled colleagues available who could have performed the surgery if contacted.

The colleagues questioned what the doctor was looking at when his sister (now a patient on the operating table) was being scrubbed and draped. It is a taboo here in black Africa, at least, maybe in other places, for one to look at the nakedness of a sibling.

The surgical procedure went well and was successful. But what could have been said if the procedure had gone otherwise? The rumours and negative insinuations would have been indescribable.

\section{The Risks and Challenges against Treating oneself and Family Members}

The American Medical Association opinion E - 8.19 deals exclusively with issues of treating oneself and immediate family members and it advised strictly and in clear terms that physicians generally should not treat themselves or members of their immediate family. The association listed out probable areas that could affect the doctor professionally:

1. Compromising professional objectivity
2. The emotions of the doctor may be unduly influenced

3. The physician may fail to probe into sensitive areas when taking history.

4. He may fail to perform intimate examinations such as pelvic and rectal examination.

5. The patient may be uncomfortable in telling some sensitive information to the physician who is a family member.

6. The physician being anxious to seeing his family member get well quickly could over-treat.

7. And if the outcome of treatment is negative, family quarrels and disunity may result.

8. The medical need of the patient may not fall within the physician's expertise and training, but because of the need to treat, he may be forced to continue treatment [1].

Similarly, the American College of Physicians (ACP) also discourages its members from treating family members. They opined that several problems can prop up when physicians treat their relatives. Agreeing with the factors above, they also considered the following:

1. The informal nature of the relationship may result in compromised care at all stages of care.

2. Associated poor history taking that may not include proper drug use history or sexual practices and pregnancies.

3. Poor or even no physical examination by the physician who may even use inappropriate equipment, since most of these consultations are done out of the hospital settings.

4. Poor objectivity by the physician because the patient is a close relation.

5. The physician may even over- investigate the patients by doing several unnecessary tests, or he may not even do any tests at all. 
6. He may avoid some necessary investigation because such tests may inflict pains.

7. The physician may deny some diagnosis because they carry poor prognosis and eventually these relatives may loose precious time needed for proper diagnosis by other non-relative physicians.

8. And because of the informal nature of most family members treatment, there is usually no proper record keeping and no documentation for others to refer to if need be $[2,3]$.

Based on all of the factors above, the Alabama Board of Medical Examiners, in agreement with the AMA resolutions advised its members to avoid treating close family members [4]. The board went further to state such actions of prescribing control drugs as unprofessional.

The College of Physicians and Surgeons of Ontario, Canada, also strongly advised physicians not to treat themselves or their family members. In agreeing with all above factors, the college further suggested that the act of treating self and family members may prevent family members and self from developing proper respectful and good relationship with their own family doctors. The reason being that there is a free at-all-times physician available at home that can be reached easily [5].

Also, there maybe the temptation for financial abuse by physician who have treated family members for free to fill vouchers for reimbursement from Health Care Management Organization (HMO). This possibility led to such health insurance companies to ban payments to physicians who have treated their family members [4,6,7].

This may not be a problem here in our locality since most hospital bills are paid directly out of pocket, with small percentage of the populace enrolled in the National Health Insurance Scheme (NHIS).

The question therefore arises that does the personal relationship between the physician and the patient bias medical judgment? Does doing a causal quick usually one system examination prevent the patients from undergoing a more thorough medical care elsewhere that can uncover any other problem? Is it appropriate to treat chronic conditions or give preventive care? When treating family members, will the physician treat outside his areas of specialization or training and therefore give substandard care? What happens if there is a bad outcome? There is also the problem of over diagnosis [8].

The AMA commented about this issue as far back as 1847, and it then advised physicians against the practice because "the natural anxiety and solicitude which he experiences at the sickness of a wife, a child, or anyone who by the ties of consanguinity is rendered peculiarly dear to him, tend to obscure his judgment and produce timidity and irresolution in his practice” [8].

\section{The Benefits of the Practices}

Some doctors feel very strongly that only themselves can be trusted to do their utmost best for their loved ones. They feel that by treating their family members, time taken off their normal duty posts is reduced [9].

Chen et al.[10] found that practicing family physicians felt occasional desire to intervene physically in the care of their family members. The researchers interviewed senior practicing family physicians who each had been in practices for over 19 years over their experiences when their own fathers had been ill and in the care of other physicians.

They reported several obstacles in their fathers care, such as poor communication and fragmented care. Many of them felt compelled to intervene emphasizing the importance of knowing the patients well ahead as a person before falling ill [10].

One of them was quoted to have said "I had to come out, what good is all that training if you can't help your own family"? [10,11].

Also, the American College of Physician noted that the patient may experience some benefits from having a physician who is either a friend or a family member provides the medical care when they are ill. Access to the physician, his attention to details and his diligence to excellence may be superior [3].

But, in emergency situation or in isolated places, where there is no other qualified physician readily available, physicians can then treat themselves or family members until such a time when another qualified physician can be accessed. Routine care for minor problems can be managed by physician - family member $[1,4]$.

Finally, it is often more convenient, or less expensive for the physician family member to provide a service than for another doctor to do so [2].

\section{Ethical Issues of the Practice}

Treatment of family members, friends and self is widespread among physicians and once a physician has treated a family member or friend even once, it may be more difficult to refuse further treatment in the future. It has been found that well over 52-84 percent of physicians engage in self treatment and that almost 100 percent of physicians are involved in the treatment of intimate patients [12].

The ethical challenges are numerous and myriad:

First, issues of autonomy are usually infringed upon, as family members may be reluctant to show preference for other doctors for the sake of not offending the physician who is a family member. So, they reluctantly accept the treatment being given. Respect for a patient's right to decide about treatment is important [1,2].

Second, issues of informed consent are brushed aside, since the treating physician is a family member and so, consent is usually assumed or not even sought for at all. Informing the patient of the risks and benefits of treatment and other alternatives are important $[1,2]$.

Third, it is the doctor's duty not to do any harm to the patient. This ethical principle of malfencence may be compromised by the inherent risks that may arise by treating family members. The challenges of over investigating, under-investigating, substandard treatment can be detrimental to the patient's well-being [9].

Fourth, is the issue of telling the truth to the patient which is enshrined in the dictate of ethics of medical practice. You are obliged to always tell the patients the truth about their health status. But a physician might withhold the truth concerning a diagnosis from a parent, but will tell the truth to another patient who is not related to him for fear of being labelled a harbinger of doom [2]. 
Last, there may occur a breach of confidentiality if the patient is a relative. Confidentiality may be hard to maintain because several other family members may insist to know what the problem is with the ill family members [2].

\section{Some Ethical Cases}

\subsection{Case I}

Youn, A. [13] reported an incidence where a surgeon operated on his own grandson who had suffered severe internal injuries following a terrible road traffic accident.

The young man needed urgent surgical intervention, and the report clearly showed that there was another qualified surgeon who was ready to do the operation. But not wanting to put the young man's life into another surgeon's hand, the grandfather - surgeon decided to operate on his grandson himself.

It was reported that the young man died several hours later in the operating room [13].

The question that might arise is whether the young man could still have died if another surgeon had operated on him?

The action of the grandfather - surgeon countered the ethical principle of beneficence - a practitioner should act in the best interest of the patient (salusaegrote supreme lex) [14].

Emotions play a big role when it comes to treating family members, and it can becloud the judgment of the physician. Such negative results as above can tear families' apart [13].

Some hospitals forbids surgeons from operating on family members and there are services that are unacceptable to offer to intimate or family members such as performing major surgery or acting as the persons primary medical provider $[2,13]$.

Here, emotions of the grandfather-surgeon was most likely disturbed, and there was another highly skilled and trusted surgeon without the family's emotional involvement present who could have done the operation. Some have argued that treating family members and other intimates is not wise because emotional involvement interferes with the physician's ability to be objective [2].

\subsection{Case II}

Oxtoby K. [15] in a BMJ career article reported untoward effect of self-treatment by physicians.

She reported two cases of suicides by physicians who apparently had been self-medicating for depressive illness.

These adverse results shows that such serious conditions need proper supervision and not to be managed by oneself [15] The author argued that physicians who prescribe drugs for themselves and those close to them could be encouraging drug addiction [15].

The ethical principle of Non-maleficence (premium non nocere) [14] which says that "first, do no harm" has been infringed on by the action of the physicians who prescribed for themselves and later died from suicide. Did the drugs they ingested lead to their suicide, was it the result of the depression or was it because there was no other doctor supervising their treatment? We suspect that harm was done here because there was no other physician involved in their management who should have noted their suicidal tendencies and probably took actions to save their lives.
Rosvold, E. A. [16] reported yet another case where a physician who was a radiologist influenced his medical management in an emergency unit of the hospital where he works, by wrongly interpreting his own chest x-ray as showing features of pneumonia, while his true diagnosis was a more severe pulmonary oedema secondary to anterior myocardial infarction. By the time a proper evaluation was done, it was too late as all instituted resuscitative efforts failed [16].

Again, the principle of non-maleficence was not adhered to by the patient-radiologist who did harm to himself by wrongly interpreting his own x-ray and leading the attending physicians on the wrong path.

It can be argued that the admitting physician should have consulted another radiologist, but the report said that there was no other radiologist present at the time and that he believed the patient-radiologist report.

\section{Who is a Family Member?}

Family member means a physicians spouse or partner, parents, children, siblings, step children, step brothers, step sisters, grandparents, grand-children, and spouses of grand-parents and grand children.

Any other individual or relation to whom the physician has personal or emotional involvement that may render the physician unable to exercise objective professional judgment in reaching diagnosis and therapeutic decisions may be considered a family member or intimate others $[5,6]$.

\section{What other National Associations Aay}

1. The Medical Council of Ireland says:

"Except for minor illness and emergences, it is not advisable for you to treat members of your own family or issue prescriptions, sick certificate or reports for them".

2. American Medical Association, "Code of Medical Ethics” opinion 8.19 says:

"Physicians generally should not treat themselves or members of their immediate families".

3. The Medical Council of New Zealand says:

"Whenever possible, avoid providing medical care to anyone with whom you have a close personal relationship" [9].

4. The Canadian Medical Association advises physicians to "limit treatment of self or members of immediate family to minor or emergency services and only when another physician is not ready available; there should be no fee for such treatment" [5].

In conclusion therefore, a quote by Sir William Osler (1849 - 1919) said "A physician who treats himself has a fool for a patient” [8].

In all, in clinical treatment of family members or intimate others, doctors are prone to omission and informalities which can compromise care and can harm patients [2]. The practice is not to be encouraged.

\section{Researchers Suggest the Following Check Questions that Provide Guide}

1. Am I trained to address this medical need? 
2. Am I too close to obtain intimate history and to cope with bearing bad news if need be?

3. Can I be objective enough not to over treat or give inappropriate treatment?

4. Is my being medically involved likely to cause or worsen family conflicts?

5. Is my relative more likely to comply with an unrelated physicians care plan?

6. Will I permit any physician to whom I refer a relative to treat that relative? [6].

7. Am I willing to be accountable to my peers and to the public for this care? [6].

\section{References}

[1] American Medical Association (2013).Opinion 8.19 - Selftreatment or treatment of immediate family members. http://www.ama-assn.org//ama/pub/physician-resources/medicalethics/code-medical-ethics/opinion819.pageAssessed 23/11/2013.

[2] American College of Physicians (1999).Internal medicine-ACP internist. Should doctors treat their relatives? ACP Internist. Ethics case study, ACP 1999. http://www.acpinternist.org/archieves/1999/01/relative.html Assessed 23/11/2013.

[3] Boughton, J. (2012).Why doctors shouldn't treat their family and friends. http://www.kevinmed.com/blog/2012/10/doctors-treatfamily-friends.html Assessed 23/11/2013.

[4] Treating family members carries risks (2010) www.burr.com/_...may_2010_Bmn/_editorial_treating_family_m embers_carries_risks (J-Griffin) PDF Assessed 23/11/2013

[5] The College of Physicians and Surgeons of Ontario (2007). Treating self and family members. http://www.cpso.on.ca/policies/policies/default.aspx? ID = 1856 . Assessed 23/11/2013.

[6] Puma, J. L., Stocking, C. B., Lavole, D.and Darling, C. A. (1991) When physicians treat members of their own families $N$. Engl. J. Med. 325: 1290-1294.

[7] Perle, S. M. (2013). American Chiropractic Association.The ethics of treating friends, family, colleagues and employees. http://www.acatoday.org/content_css,cfm? CID = 3382 Assessed 23/11/2013.

[8] Huff, J. E. The doctor is (always) in: Treating oneself and one's family.

www.ncmedboard.org/../the_doctor_is_always_in_treating_onesel f_and_ones_family Assessed 23/11/2013.

[9] GMC (Good Medical Practice (2013). Treating family members.Should doctors provide medical care for their families? http://www.gmc_uk_org/guidiance/10247.asp

[10] Chen, F. M., Rhodes, L. A., Green, L. A. (2001). Family physicians personal experiences of their fathers health care. $J$. Fam. Pract. 50 (9): 762-766.

[11] Chen, F. M., Feudtner, C., Rhodes, L. A. and Green, L. A (2001).Role conflicts of physicians and their family members: rules but no rulebook. West J. Med. 175 (4): 236-239.

[12] Latessa, R. and Ray L. (2005). Should you treat yourself, family or friends? Fam. Pract. Manag: 12 (3): 41-44.

[13] Youn, A. why doctors shouldn't treat family members http://thechart.blugs.cnn.com/2012/01/09/why-doctors-shouldn'ttreat-family-members/ Accessed 17/04/2014.

[14] Medical ethics. wikipedia, free encyclopedia en. wikipedia.org/wiki/medical_ethics Accessed 25/10/2013.

[15] Oxtoby, K. Doctors self prescribing. BMJ careers; Doi: http://careers.bmj.com./careers/advice/view-articles.html? ID = 20006142 Accessed 14/04/2014.

[16] Rosvold, E. O. Doctor, Don't Treat Thyself http://www.webmm.ahrq.gov/case.aspx? Case ID = 71 . 